\title{
REVIEW
}

\section{New concepts in prolactin biology}

\author{
Sophie Bernichtein ${ }^{1}$, Philippe Touraine ${ }^{1,2}$ and Vincent Goffin ${ }^{1}$ \\ ${ }^{1}$ Inserm, Unit 845, Research Center Growth and Signaling, University Paris Descartes, Faculty of Medicine, Necker site, Paris 75015, France \\ ${ }^{2}$ APHP, Département d'Endocrinologie et Médecine de la Reproduction, Centre des Maladies Rares Gynécologiques, and University Pierre et Marie Curie, \\ GH Pitié-Salpêtrière, F-75651 Paris Cedex 13, France \\ (Correspondence should be addressed to V Goffin; Email: vincent.goffin@inserm.fr)
}

\begin{abstract}
Human prolactin (PRL) is currently viewed as a hormone of pituitary origin, whose production (i.e. serum levels) is controlled by dopamine, whose biological actions relate exclusively to lactation and reproductive functions, for which any genetic disorder is yet to be identified, and whose unique associated pathology is hyperprolactinemia. Both experimental studies and human sample/cohort-based investigations performed during the past decade have considerably widened our perception of PRL biology: i) there are now strong epidemiological arguments supporting the fact that circulating PRL is a risk factor for breast cancer, ii) in addition to the endocrine hormone, locally produced PRL has been documented in several human tissues; there is increasing evidence supporting the tumor growth potency
\end{abstract}

of local PRL, acting via autocrine/paracrine mechanisms, in both rodent models, and human breast and prostate tumors, iii) the first functional germinal polymorphisms of the PRL receptor were recently identified in patients presenting with breast tumors, which involve single amino acid substitution variants exhibiting constitutive activity, iv) human PRL analogs have been engineered, which were shown in experimental models to down-regulate the effects triggered by local PRL (competitive antagonism) or by the constitutively active receptor variants (inverse agonism). The aim of this review is to discuss these novel concepts in PRL biology, including their potential pathophysiological outcomes.

Journal of Endocrinology (2010) 206, 1-11

\section{Classical view}

Prolactin (PRL) was discovered 80 years ago (Stricker \& Grueter 1928, Riddle et al. 1933). In Endocrinology textbooks, PRL is defined as a pituitary-secreted polypeptide hormone which was named for its stimulatory action on lactation. Various animal models, including mice deficient for PRL (Horseman et al. 1997) or for its receptor (PRLR; Ormandy et al. 1997) have unambiguously confirmed this issue; these studies also shed light on the essential role of the PRLR/STAT5 pathway in mammopoiesis (Liu et al. 1997). In addition, these germline models of permanent PRLR signaling failure were very useful to reveal or confirm the other multiple physiological actions modulated by PRL, including actions on behavior and on the brain in general, metabolism, immune responses, and electrolyte balance (for reviews, Bole-Feysot et al. (1998), Dorshkind \& Horseman (2000) and Ben Jonathan et al. (2008)). Despite the fact that almost 300 functions or targets could be identified for this hormone in various species, the question remains open as to which of them are really relevant in humans. One of the difficulties preventing a clear understanding is that no genetic disease related to the genes encoding human PRL or its receptor has been identified yet; therefore we lack a definitive clinical model of isolated PRL deficiency that could be used to identify the functions that depend on, or are modulated by PRL. It should be noted that even its main functions, i.e. actions on mammary gland development, are in fact poorly documented in humans, and our understanding is mainly from lessons learned using animal models.

Hyperprolactinemia is currently the only PRL-related pathology of concern to clinicians, which probably reflects our lack of knowledge of this 'old' hormone. Pathological hyperprolactinemia is defined as circulating PRL levels above normal range, which occurs in conditions other than pregnancy and lactation, when physiological hyperprolactinemia occurs. The major cause of pathological hyperprolactinemia involves tumors of pituitary lactotroph cells (prolactinomas), the main source of PRL in the organism. Pathological hyperprolactinemia results in galactorrhea and oligo/amenorrhea in women, impotence in men, and loss of libido and infertility in both sexes (Molitch et al. 1997). For $85-90 \%$ of patients, this condition is efficiently cured using synthetic analogs of dopamine, the physiological negative 
regulator of PRL production by lactotrophs (Molitch 2003). In addition to normalized circulating PRL levels, which solves systemic effects of hyperprolactinemia, such treatments also reduce the volume of the pituitary tumor. Antipsychotic medications are also known to cause moderate hyperprolactinemia (Knegtering et al. 2003, Hummer \& Huber 2004, Goffin et al. 2006). This is in agreement with the fact that their mechanism of action involves blockade of dopamine D2 receptors. Dopamine agonist therapy is usually not advisable for treating associated symptomatic hyperprolactinemia, although this approach has been used successfully in some instances (Molitch 2005a).

The role of PRL in mammary cancer was suggested several decades ago, mainly based on observations involving animal models (Welsch \& Nagasawa 1977). However, as true for the multiple physiological functions attributed to PRL based on genetically modified models (Bole-Feysot et al. 1998), the relevance of extrapolating the tumorigenesis data obtained in animal models to humans has always been questioned. One of the reasons is that studies involving human patients failed to be conclusive. First, initial studies have shown that treatment using bromocriptine, the prototype dopamine agonist, did not improve the condition of advanced breast cancer patients despite reduction of their circulating PRL levels (Bonneterre et al. 1988, Anderson et al. 1993). Second, epidemiological studies performed during the 80's and 90's were unable to reach unified conclusions regarding any correlations between circulating PRL levels and breast cancer risk (for reviews, Clevenger et al. (2003) and Tworoger \& Hankinson (2008)). Although these therapeutic trials and epidemiological studies involved only a small number of subjects to be conclusive, the take-home message was negative, which largely contributed to nourish the doubts regarding the potential involvement of PRL in human tumorigenesis. As a consequence, based on our current understanding of PRL pathophysiology, dysfunctions of this hormonal system are limited to prolactinomas and downstream hyperprolactinemia, which is no longer considered as a major problem in human health.

The past 10 years or so have been very rich in experimental and clinical reports that have considerably modified this classical view of PRL pathophysiology. The aim of this article is to overview four major advances in the field (Fig. 1):

- First, large-scale epidemiological studies have been performed that unambiguously reveal that high-normal circulating levels of PRL increase breast cancer risk.

- Second, locally produced PRL has been documented in various tissues, especially in human species, providing the molecular basis for an autocrine/paracrine mechanism of action for this hormone, classically considered as an endocrine factor; in addition, functional studies using animal models, and expression studies of human samples, brought strong arguments supporting the role of local PRL in breast and prostate tumorigenesis.

- Third, the only gain-of-function variants of the PRLR were reported very recently in patients presenting with
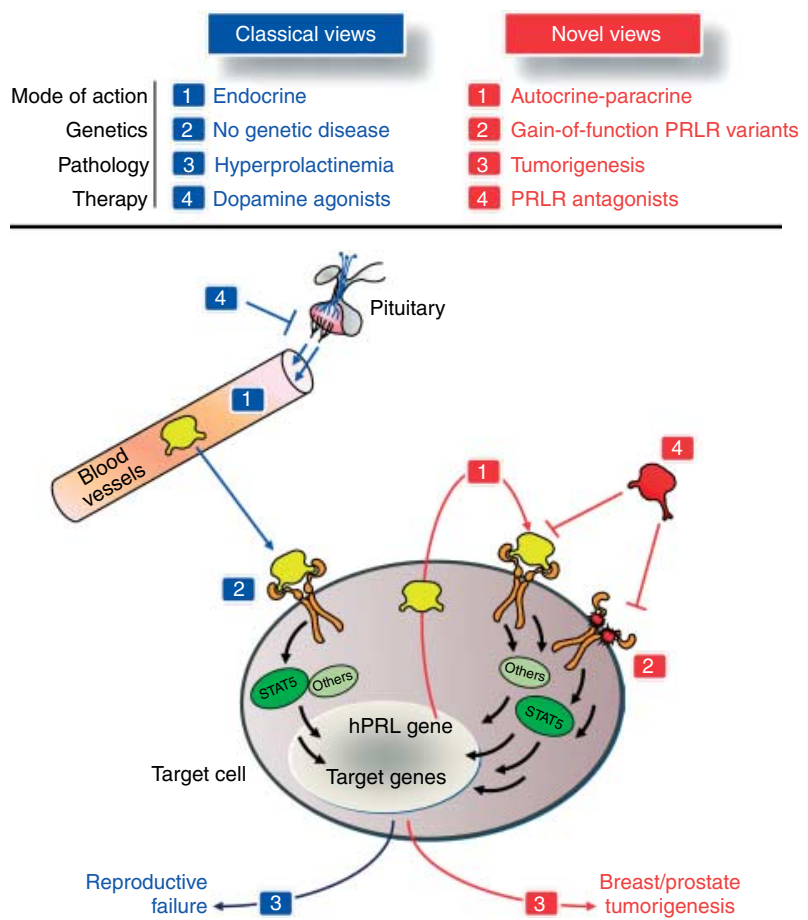

Figure 1 Novel views in PRL biology. The four aspects of PRL biology that are discussed in this article are schematized. The classical view is represented in blue, while novel concepts are shown in red. The latter should be considered as additional to the classical view, and do not substitute for principles that have been validated over the years. As the main intracellular cascade downstream the PRLR, STAT5 is the only one represented; for others, see references in text. Amplification of local mechanisms triggering the PRLR (autocrine/paracrine PRL and gain-of-function PRLR variants) is symbolized by the larger number of arrows.

breast tumors, further supporting the participation of increased PRLR signaling in human tumorigenesis.

- Fourth, a novel class of compounds with therapeutic potential to target PRLR signaling, namely competitive PRLR antagonists, have been developed and characterized in a wide series of experimental set-ups. Such molecules are candidates when dopamine agonists are intrinsically inefficient.

\section{Recent advances in the field of PRL research}

Circulating PRL as a risk factor for breast cancer

Classical view There is no clear evidence for an association between PRL levels and breast (or other tissues) cancer risk. Thus, hyperprolactinemia remains the unique clinical pathology associated with PRL.

Discussion In order to determine whether high PRL levels constitute a risk factor for cancer, conventional wisdom would suggest looking at hyperprolactinemic patients. 
However, we are not aware of any large-scale study that focused on cancer occurrence in patients presenting with prolactinoma, and even less in those hyperprolactinemic patients whose PRL levels could not be normalized after dopamine agonist treatment (Molitch 2003). Actually, the only available data refers to a small cohort of 67 women presenting with prolactinomas, for which no increased incidence rate of malignancy, including breast cancer, could be demonstrated compared with controls (Popovic et al. 1998). A prospective, case-controlled study involving 20 men with prolactinoma investigated the possible risk for prostate hypertrophy (Colao et al. 2004). While experimental models have indicated that hyperprolactinemia correlates with benign prostate hyperplasia and hypertrophy in rodents (see below; Van Coppenolle et al. 2001, Kindblom et al. 2003), the study by Colao et al. suggested the opposite in humans. Although these data may be viewed as puzzling, they are not so surprising if one remembers that hypogonadism is frequently observed in hyperprolactinemic patients, therefore lower exposure to estrogens and androgens may partially mask the eventual increased risk associated with high PRL levels (Tworoger \& Hankinson 2008).

The vast majority of epidemiological data that are currently available involve comparisons between high versus low PRL levels in normoprolactinemic subjects. The epidemiological data related to PRL and breast cancer risk have been exhaustively reviewed in a recent article (Tworoger \& Hankinson 2008). In this paragraph, we will only address the major conclusions of the most relevant studies; the reader is invited to refer to the excellent above-mentioned review for additional details and references. The numerous studies can be stratified into three groups: retrospective casecontrolled studies, prospective case-controlled studies of small sample size, and prospective case-controlled studies of large sample size.

More than 20 retrospective case-controlled studies most often including small cohorts have been published within the past 4 decades (for references, see Tworoger \& Hankinson (2008)). Unfortunately, the bottom line remained inconsistent, as roughly half of them reported an associated risk with PRL levels, while the others achieved the opposite conclusion. Some of these studies are of concern regarding the methodology used, e.g. PRL levels were often assessed after breast cancer was diagnosed and/or treated, which could not reflect pre-disease exposure to the hormone. Globally, the take-home message from these studies is inconsistent.

The number of prospective studies is smaller. Those involving small sample size (maximum 71 cases) found at best a moderate risk, which could not be validated due to the limited number of subjects included (for references, see Tworoger \& Hankinson (2008)). Two large prospective studies used a nested case-control design in the Nurses' Health Studies (NHS and NHS II). The combination of these two studies achieved 492 cases for pre-menopausal women (and 1001 controls), which represents nearly $80 \%$ of published pre-menopausal cases (Tworoger et al. 2007). There was an overall $40 \%$ increase in breast cancer risk for women with PRL levels in the highest versus lowest quartile of normal range $(P$ trend $=0 \cdot 05)$. With respect to post-menopausal women, NHS and NHS II studies combined 915 cases with 10-year follow-up, which again represents nearly $80 \%$ of published cases for post-menopausal women. There was a $30 \%$ increase in breast cancer risk $(P$ trend $=0 \cdot 01)$. One of the main take-home messages from these studies is that PRL association with breast cancer risk did not differ depending on menopausal status, invasive versus localized cancer, or ductal versus lobular cases (Tworoger \& Hankinson 2008). In contrast, there was a clear difference with respect to estrogen receptor (ER) status, as risk reached 1.6 when considering only ER-positive breast cancer $(0.9$ for ER negative), while it remained independent of sex steroid levels. One of the methodological concerns regarding epidemiological studies involving single PRL measurements is reliability (reproducibility), as PRL levels are known to be modestly stable within a woman over time. Reproducibility studies have been conducted within NHS and NHS II studies, by collecting three samples over 3 years in a subset of 113 women (Tworoger et al. 2006, 2007). After correction, the relative risk for breast cancer increased to 1.7 for all cases, and to $2 \cdot 1$ for ER-positive cases, which is very similar to the risk associated with estradiol (Key et al. 2002).

With respect to prostate cancer, data is much more sparse than for breast cancer. The largest study published to date involved the Northern Sweden Health and Disease Cohort study, which involved follow-up of nearly 30000 men, including 144 subjects diagnosed with prostate cancer (Stattin et al. 2001). This study concluded that there was no correlation between PRL levels and cancer risk.

Novel views There is now clear evidence that high-normal circulating PRL levels increase breast cancer risk in both preand post-menopausal women. The exact mechanism underlying this increased risk remains to be clarified. Beyond proliferative effects - which are not so marked using in vitro proliferation assays of classical breast cancer cell lines such as MCF-7 or T-47D - the various roles of PRL in breast cancer are currently being deeply investigated. It has been proposed that PRL may promote mammary tumor initiation via the JAK2/STAT5 signaling pathway, but as this cascade also maintains cell differentiation, it may also contribute to suppress invasive characteristics (Nevalainen et al. 2004, Wagner \& Rui 2008, Tran et al. 2010). Otherwise, the concept is emerging that PRL could favor cell motility and confer resistance to chemotherapy, and thereby contribute to metastasis dissemination (for reviews Clevenger et al. (2003) and Lapensee \& Ben Jonathan (2010)). Such diverse effects may be mediated by distinct signaling cascades. Future investigations are obviously required to better understand the role of this hormone in breast cancer, which could restore the interest (and perhaps determine the timing) of using antiPRL drugs targeting either pituitary PRL production or PRLR activation in subsets of patients. Finally, the positive 
association between circulating PRL levels and tumorigenesis does not exclude other mechanisms that might be involved in tumorigenesis, especially with respect to the prostate cancer for which no such association was identified. One such mechanism involves locally produced PRL.

\section{PRL, not only an endocrine hormone}

Classical view PRL is viewed as a classical endocrine hormone, produced by pituitary lactotroph cells, and delivered to its numerous target tissues via the blood circulation.

Discussion In addition to circulating PRL acting via endocrine routes, there is clear evidence that several human tissues also express PRL. This is true for the mammary gland, the prostate, the skin, the decidua, the brain, some immune cells, adipocytes, and several others (for review, Ben-Jonathan et al. (1996)). As the PRLR is also expressed in these tissues, co-expression of both partners suggests the existence of an autocrine-paracrine loop of action, which could be demonstrated using various functional approaches (see below). Even if such a mechanism is supposed to occur in many tissues, our understanding of its impact in physiological (i.e. non-pathological) conditions remains very limited. For example, local PRL was proposed to play a role in i) mammopoiesis, based on experiments using PRL-deficient mice (Naylor et al. 2003), ii) nociception, based on experiments using rat trigeminal sensory neurons (Diogenes et al. 2006), or iii) dermatological bioregulation, based on experiments using organ-cultured human hair follicles (Foitzik et al. 2009, Ramot et al. 2010). Even if these examples are not aimed at being exhaustive, the paucity of knowledge of local PRL contrasts with the pleiotropic actions usually linked to the endocrine hormone (Bole-Feysot et al. 1998). There are at least two reasons for that:

First, although extrapituitary PRL has been occasionally reported in animals, it appears to be much more commonly observed in human species; therefore, rodent models have in general proven to be less suitable to address the physiological role of local PRL. This particular feature presumably reflects species-specific mechanisms of PRL gene regulation, which includes the existence of two distinct promoters in human, but not in rodent $\mathrm{Prl}$ gene (for reviews, Ben-Jonathan et al. (1996) and Baudhuin et al. (2002)). In addition to the classical 'pituitary' promoter, a second promoter, referred to as 'extrapituitary' promoter, was identified $\sim 5.8 \mathrm{~kb}$ upstream of the initiation site of human PRL gene. Interestingly, comparative genomic analysis of this region revealed that the extrapituitary promoter occurs within a retroviral long terminal repeat-like transposable element that could also be identified in the PRL gene of some monkeys, but not of dog, mouse or rat (Gerlo et al. 2006). The transcriptional regulation of the extrapituitary promoter remains poorly known. According to initial studies performed using lymphocytes and decidual cells (Gellersen et al. 1994),
PRL expression in non-pituitary tissues has been classically considered to be dopamine and Pit-1 (listed as POU1F1 in the MGI Database) independent. Various factors have been proposed to regulate $P R L$ gene expression in extrapituitary sites, e.g. insulin, transforming growth factor- $\beta$ or progesterone in adipose tissue (Zinger et al. 2003, Hugo et al. 2008). However, a common regulator to all non-pituitary sites, if it exists, is yet to be identified. A very elegant humanized transgenic rat model was recently generated, in which expression of bioluminescent (luciferase) and fluorescent (GFP) reporters were put under the transcriptional control of PRL gene promoters (Semprini et al. 2009). This model should be very useful for identifying stimuli regulating extrapituitary expression of PRL in vivo. It may be misleading to consider that the dichotomy of promoter usage in pituitary versus other sites is absolute. Indeed, while PRL mRNA transcribed from the extrapituitary promoter is $\sim 150 \mathrm{bp}$ longer compared with that transcribed from the pituitary promoter, both mRNA were shown to occur in various human breast/prostate cancer cell lines or biopsies (ShawBruha et al. 1997, Dagvadorj et al. 2007). Moreover, it has been shown that in the SK-BR-3 human mammary tumor cell line, the sole pituitary promoter was active, despite of the absence of Pit-1 in mammary cells (Manfroid et al. 2005). Whatever our still limited understanding of PRL promoter usage, the rareness of extrapituitary $P R L$ gene expression in rodents led to the fact that local PRL escaped (almost) all non-genetically modified animal models (see below).

Second, although PRL mRNA was identified in various human non-pituitary tissues/cell lines (Reynolds et al. 1997, Shaw-Bruha et al. 1997, Touraine et al. 1998, Dagvadorj et al. 2007), the protein itself is much more tricky to detect (Ginsburg \& Vonderhaar 1995). In cell cultures, it is produced at very low yields, with no evidence of pulsatility or of secretory granules, and it is rapidly diluted in culture medium. It is possible that within a tissue, the limited volume of extracellular space allows the protein to locally reach higher concentrations, which is currently unknown. In the current state of the art, any specific feature which could distinguish pituitary from extrapituitary PRL is yet to be identified. Therefore, although PRL produced by peripheral tissues is classically assumed to remain within its production site, its eventual contribution to the pool of circulating PRL has been impossible to evaluate. It has been reported that hypophysectomized breast cancer patients regained near-normal PRL levels within several weeks of surgery (Lachelin et al. 1977) suggesting that, in some circumstances, extrapituitary sources may contribute to circulating PRL levels. In the absence of known negative regulator of extrapituitary PRL production, this issue remains impossible to assess (Ben-Jonathan et al. 1996). In conclusion, extrapituitary PRL is very difficult to identify by other means than immunohistochemical analyses of human biopsies, which at best allows semi-quantitative evaluation of its production level (Nevalainen et al. 1997, Reynolds et al. 1997, McHale et al. 2008). These limitations clearly hamper reliable tracking of time- or state-dependent 
fluctuations of its expression, which currently precludes our understanding of its functional role in non-pathological conditions.

The functional activity of extrapituitary PRL has been mainly addressed using experimental models related to tumorigenesis. The first investigations involved interference with PRL secretion or action in human cancer cells. This was performed using breast or prostate cancer cell lines treated using PRL neutralizing antibodies (Ginsburg \& Vonderhaar 1995) or receptor antagonists (Dagvadorj et al. 2007; see section on 'Anything beyond dopamine agonists'), or by generating PRL-deficient breast cancer cells from parental MCF-7 cells expressing PRL (Brockman et al. 2002, Schroeder et al. 2002; for reviews, Clevenger et al. (2003) and Goffin et al. (2005)). All these studies pointed to the proliferative/anti-apoptotic role of autocrine/paracrine PRL. As mentioned, due to the rareness of extrapituitary PRL expression in rodents, knockout strategies were rarely used to address functional issues (Naylor et al. 2003). Actually, animal models generated to date all involved the opposite strategy, i.e. the generation of tissue-specific PRL transgenic models aimed at recreating the autocrine/paracrine loop found in human tissues. Prostate-specific PRL transgenic mice were reported to develop precocious prostate hypertrophy (Kindblom et al. 2003). Ongoing studies in our laboratory show that these benign tumors developed to invasive adenocarcinomas in 18-20-month animals, highlighting the oncogenic potency of locally produced PRL. Similar findings were reported for virgin mammary-specific PRL transgenic females, which first displayed various pre-neoplastic lesions before eventually developing ER-positive and ER-negative adenocarcinoma at a median age of 16 months (RoseHellekant et al. 2003). When mammary expression of human PRL was driven by the whey acidic protein promoter (WAP, a milk protein gene), meaning onset of transgene expression occurred when the gland is already far in the differentiation process, various benign anomalies were reported, but no carcinoma (Manhes et al. 2006). These models of local PRL over-expression (for review, Arendt \& Schuler (2008)) clearly demonstrated the tumor growth-promoting potency of locally produced PRL, which was reminiscent to that of circulating PRL based on the similar mammary and prostate phenotypes of transgenic mice over-expressing PRL systemically (Wennbo et al. 1997a,b).

As always, the question remaining is the extent to which these observations are relevant to human tumors. Recent investigations involved immunohistochemical analyses of PRL expression in mammary and prostate biopsies, where its expression levels were compared between cancer and healthy tissue or benign lesions (Li et al. 2004, McHale et al. 2008). Despite the difficulties linked to the use of this approach for quantification purposes, the level of PRL expression was clearly found to be higher in cancer for both tissues. For the prostate, a positive correlation with tumor grade (Gleason score) and STAT5 phosphorylation could also be established, which suggested the involvement of the
PRLR/STAT5 pathway in prostate tumorigenesis. This hypothesis was nicely confirmed at the experimental level using models over-expressing or, in contrast, down-regulating STAT5 expression/activity in human prostate cancer tumors xenografted into immunodeficient mice (Dagvadorj et al. 2008). Finally, for the breast, upregulation of PRL labeling paralleled those of NEK3 and PIAS3, two regulators of PRLR signaling (McHale et al. 2008).

Novel views Arguments supporting the tumor growthpromoting potency of local PRL in humans are emerging. Beyond increased local expression of the hormone, some (but not all) authors have also reported concomitant upregulation of PRLR expression in breast and prostate tumors (Mertani et al. 1998, Touraine et al. 1998, Leav et al. 1999, Gill et al. 2001). This strengthens the idea that amplification of the autocrine/paracrine loop may be one of the mechanisms underlying the participation of local PRL in tumorigenesis. However, assessment of this hypothesis at the functional level has been persistently hampered due to the absence of drugs capable of blocking PRL synthesis in peripheral tissues. Alternative strategies involving neutralizing PRLR antibodies and even more PRLR antagonists have opened new areas of research in this field (see section on 'Anything beyond dopamine agonists'). Finally, although the involvement of local PRL in tumorigenesis has retained increasing attention within the past 15 years (Clevenger et al. 2003, Goffin et al. 2005), another mechanism potentially participating in local amplification of PRLR signaling in tumor contexts has recently emerged, and involves gain-of-function PRLR variants.

\section{Genetic alterations of the PRLR gene}

Classical view There is no pathology associated with genetic anomalies of $P R L$ or $P R L R$ genes.

Discussion In contrast to what is observed for all other pituitary hormones, no mutation of the $P R L$ or $P R L R$ genes has been identified yet. Isolated or familial PRL deficiency (hypoprolactinemia) and PRL resistance have been proposed as possible mechanisms responsible for puerperal alactogenesis observed in a few patients (Zargar et al. 1997, 2000, Saito et al. 2007). However, no investigation was conducted to support any genetic cause underlying these functional defects. Hypoprolactinemia is also observed in patients harboring mutation of transcription factors involved in pituitary ontogenesis, e.g. Pit-1 (for reviews, Andersen \& Rosenfeld (2001) and Davis et al. (2010)). Nevertheless, as more than a single cell lineage are affected by such mutations, the multiple hormonal deficiencies displayed by these patients do not provide a clear picture of those strictly dependent on PRL. Briefly, a human genetic model is currently lacking to highlight the involvement of PRL in pathophysiology.

Based on the fact that the breast is - and remains - the main target of PRL, search for mutations of the PRL system 
(ligand and receptor) has been historically performed in breast cancer patients. The first report was conducted in 30 patients presenting with invasive ductal or lobular breast cancer (Glasow et al. 2001). No missense alteration of the PRLR gene was identified in patients nor in 20 healthy controls (the PRL gene was not evaluated). A second study included 38 invasive carcinomas and 100 healthy controls (Canbay et al. 2004). The PRL gene was not investigated in that study. One identical missense single nucleotide polymorphism (SNP) was observed in the PRLR gene of two patients, and none in that of the control subjects. This germinal variant encoded a receptor variant harboring one residue substitution in the extracellular domain (Leu substituted for Ile146; Fig. 2). No functional investigation was conducted on this variant, and the number of patients was too small to provide significant association with the disease. Vaclavicek et al. (2006) investigated the PRL and PRLR genes in 441 familial breast cancer cases and 522 age-matched controls. No increased risk was associated with individual non-coding SNPs in the PRLR, but the combination of PRL and PRLR risk haplotypes was associated with an increased relative risk of $2 \cdot 6$ (95\% CI: $1 \cdot 4-4 \cdot 6, P$ trend=0.007). Finally, the MultiEthnic Cohort study involved 1615 breast cancer cases and 1962 control subjects (Lee et al. 2007). This comprehensive analysis covering both PRL (59 kb) and PRLR (210 kb) loci identified no significant association between common variations in these genes and breast cancer risk (or plasma PRL levels). The bottom lines of these four studies are that i) only one missense SNP was identified in the PRLR gene

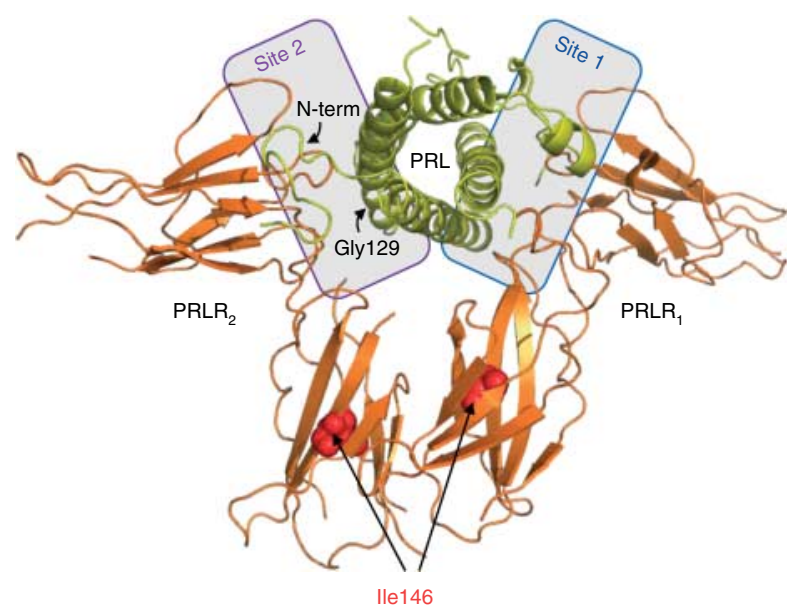

Figure 2 Crystal structure of the PRL-PRLR 2 complex. The structure of PRL (green) bound to two moieties of the PRLR extracellular domain (orange) has been solved recently (Broutin et al. 2010). This picture shows the two binding sites of PRL to its receptor. The two main features within site 2 are localized: Gly129 and the $\mathrm{N}$-terminus. The mutation of these two structural components is required to obtain a pure PRLR antagonist (Del1-9-G129R-hPRL). Isoleucine 146 is also represented (red). Substitution of a leucine for Ile146 leads to constitutive activity without affecting ligand binding (see text).
(I146L), and none in the PRL gene, ii) at best, associations could be suggested for combined non-coding SNPs, and iii) in any case, none of the associations proposed were supported by functional investigations (e.g. gene expression, mRNA stability, protein properties, etc).

Beyond breast cancer, breast pathologies include a wide panel of benign breast disease (BBD). The etiology of BBDs is poorly known, especially for those presenting with rare features (Santen \& Mansel 2005). In addition to the morbidity linked to the disease itself, BBDs represent an important risk factor for developing a cancer (Hartmann et al. 2005, Worsham et al. 2009). Multiple breast fibroadenoma (MFA) is a rare BBD of unknown etiology, which is defined by the presence of at least three lesions (adenomas) simultaneously in one breast (Hughes et al. 2000). We and others have demonstrated that the PRLR is expressed in mammary biopsies from various benign and malignant breast lesions (Clevenger et al. 1995, Mertani et al. 1998, Touraine et al. 1998, Gill et al. 2001). Therefore, based on the essential role of the PRL system in mammary gland morphogenesis and differentiation, we hypothesized that PRLR-triggered signaling cascades could participate in benign breast tumorigenesis, as already suggested for various growth factors (Courtillot et al. 2005). In such a context, we conducted a study aimed at identifying genetic anomalies of PRL and PRLR genes in a population of patients presenting with MFAs (Courtillot et al. 2010). We only focused on coding regions (exons) of these genes. While no missense SNP was identified in PRL gene, we found three germline, heterozygous missense SNPs in the PRLR gene (Courtillot et al. 2010). This result was particularly encouraging given the paucity of coding SNP reported in the literature and databases for this receptor. Two of them involved the extracellular domain (exon 5/I76V, exon 6/I146L), and one involved the intracellular domain (exon 10/E554Q). The latter was identified in one patient only. Otherwise, PRLR-I76V was identified in both patient and control populations, suggesting that it is a real polymorphism independent of the disease. More interestingly, the third one (PRLR-I146L; Fig. 2) was harbored by four patients $(n=95)$, and none by the control subjects $(n=194$; $P<0 \cdot 01$; Courtillot et al. 2010). Even more intriguing, one should note that two earlier studies focused on breast cancer (see above) also identified these SNPs in patients and not in control populations (Canbay et al. 2004, Vaclavicek et al. 2006). In these studies, however, no significant association was found between PRLR-I146L and the disease, which may be due to the low number of patients in which exon 6 was sequenced ( $n=38$ and 23 respectively) and the low prevalence of this $\operatorname{SNP}(n=2$ and 1 respectively, i.e. $\sim 5 \%$ of patient populations).

We characterized the functional impact of I146L substitution on PRLR properties, using several in vitro cell-based bioassays involving various readouts, that were specifically developed for testing human lactogens (Bernichtein et al. 2003a). We demonstrated that the sole I146L substitution was sufficient to convert the PRLR into a constitutively active 
receptor (Bogorad et al. 2008). This means that in the absence of any PRL stimulation, PRLR-I146L triggers downstream signaling cascades (Stat5 and MAPK), which protects cells from apoptosis and/or stimulates their proliferation. These observations were confirmed using stably transfected MCF-7 breast cancer cells exhibiting the 'heterozygous' PRLR profile observed in the four MFA patients harboring one PRLR-I146L allele (Bogorad et al. 2008, Courtillot et al. 2010). The affinity of the PRLR for PRL was not affected by I146L substitution, and in most assays, PRL stimulation had an additive effect over PRLR-I146L constitutive activity, leading to higher levels of activation compared with cells expressing the wild-type receptor stimulated by equivalent PRL doses (Bogorad et al. 2008).

PRLR-I146L is the first ever reported functional mutation of the PRLR associated with a human disease. Interestingly, PRLR-I76V also displayed some level of constitutive activity, albeit to a much lesser extent than PRLR-I146L (Courtillot et al. 2010). In total, $15 \%$ of our MFA patients appeared to harbor one of these PRLR allelic variants exhibiting constitutive activity, strongly suggesting that enhanced PRLR signaling may be one of the molecular pathways involved in MFA etiology, and perhaps more globally, in breast pathogenesis. Interestingly, one of the four PRLRI146L patients initially diagnosed with MFA developed a rapidly evolutive grade III invasive ductal carcinoma at the age 38, suggesting the possible involvement of this receptor variant in benign/malignant transition. Although one must remain very cautious not to over-interpret such a case report, this observation underlines the need for appropriate epidemiological and functional data supporting this hypothesis.

Novel views PRLR-I146L is the first functional genetic variant identified for the PRLR. Based on its gain-offunction properties, suspecting its involvement in breast tumorigenesis seems reasonable. Various investigations currently performed in our laboratory are aimed at better delineating the impact of PRLR-I146L in breast cancer, which includes the use of diverse breast cancer cell lines and the analysis of patient cohorts. Another challenge is to understand the molecular mechanisms underlying the gainof-function properties of PRLR-I146L. The recently determined structure of the homodimerized rat PRLR extracellular domain bound to PRL will be a useful tool in awaiting the determination of PRLR-I146L threedimensional structure (Broutin et al. 2010). The intrinsic PRL-independent activity of PRLR-I146L also implies the use of alternative approaches to dopamine agonists for down-regulating its downstream effects, which may become therapeutically relevant once its impact on breast cancer is better delineated. Compounds specifically targeting the receptor itself, or its major downstream signaling cascades, are necessary. PRLR antagonists are obvious candidates.
Anything beyond dopamine agonists?

Classical view Dopamine agonists are the unique compounds relevant to treat disorders linked to excess PRL levels.

Discussion There is no doubt that dopamine agonists (bromocriptine, cabergoline, etc.) are very efficient drugs to treat hyperprolactinemic patients presenting with prolactinoma (Molitch 2005a). However, as described above, such compounds are per se inappropriate to target locally produced PRL (whose expression is dopamine independent) or constitutively active receptors (whose basal activity is independent of PRL). At best, dopamine agonists could eventually prevent additive effects of endocrine and local mechanisms triggering PRLR signaling, which remains to be demonstrated experimentally. New strategies targeting the receptor itself, and not the central production of its ligand, have been a field of intense investigations during the past decade.

One of the pioneering reports published by the group of Vonderhaar showed the ability of neutralizing anti-PRL antibodies to reduce proliferation of breast cancer cell lines in vitro (Ginsburg \& Vonderhaar 1995). However, to the best of our knowledge, preclinical development of anti-PRL monoclonals is yet to be reported. In contrast, the development of modified PRLR ligands based on the PRL core has been very productive. Three types of compounds can be distinguished: competitive PRLR antagonists (that target the PRLR only, prototype is Del1-9-G129R-hPRL; Bernichtein et al. 2003b), chimeric antagonists (bifunctional molecules targeting two receptors and/or exhibiting increased half life; Zhang et al. 2002), and alternative agonists (that selectively activate downstream PRLR targets, prototype is S179D-hPRL; Walker 2007). The various types of antagonists have been recently reviewed (Goffin et al. 2005, 2007, Tallet et al. 2008), therefore we will only focus on data recently obtained using Del1-9-G129R-hPRL, the sole pure PRLR antagonist reported to date.

The development of this compound started in our laboratory in the nineties, through the engineering of G129R-hPRL variant, in which glycine 129 was replaced by a sterically hindering arginine residue (Goffin et al. 1994; Fig. 2). This substitution was designed to alter the functionality of so-called binding site 2 of human PRL, which was later confirmed using surface plasmon resonance analyses demonstrating that any substitution of this conserved residue prevented interaction between Gly129 hPRL mutants and the soluble extracellular domain of the PRLR (Jomain et al. 2007). Despite the fact that it exhibited antagonistic properties, G129R-hPRL also displayed residual agonism that was more easily detectable in some assays than others (Bernichtein et al. 2003a, Goffin et al. 1996, 2005). Using both structural and functional approaches, we identified the $\mathrm{N}$-terminus of the molecule as responsible for this residual agonism. Hence, deletion of nine N-terminal amino acids led to a compound displaying pure antagonistic properties (Bernichtein et al. 2003b, Jomain et al. 2007, Broutin et al. 2010). 
The properties of Del1-9-G129R-hPRL have been characterized by several collaborators using a wide panel of bioassays, involving various cell types of mouse, rat, or human origin (for review, Tallet et al. (2008)). First, all studies published so far confirm the absence of residual agonism of this analog. Accordingly, we generated transgenic mice expressing this antagonist systemically, and we have failed to observe any 'hyperprolactinemic phenotype', which contrasted with transgenic mice expressing the first generation antagonist G129R-hPRL (Tallet et al. 2008 and unpublished data). With respect to antagonistic properties, the ability of Del1-9G129R-hPRL to inhibit the actions mediated by exogenous/ circulating (co-injected) PRL has been widely demonstrated, providing the antagonist was added in molar excess over the agonist to compensate its lower affinity for the PRLR (for reviews, Goffin et al. (2005) and Tallet et al. (2008)). Inhibition of the effects induced by locally produced growth factor is a more tricky challenge. In vitro, Del1-9-G129R-hPRL was shown to antagonize the survival effect mediated by autocrine PRL/STAT5 cascade in prostate cancer cell lines (Dagvadorj et al. 2007). Its ability to counteract the effects induced by local PRL has also been demonstrated in other cell types, including sensory neurons (Diogenes et al. 2006), human uterine fibroblasts (Eyal et al. 2007), and more recently in human hair follicles (Ramot et al. 2010). In these assays, however, it is difficult to state whether the antagonist achieved complete inhibition of the pathways/effects specifically activated by autocrine PRL. This issue was partly solved using a transgenic approach. Double transgenic mice expressing the antagonist systemically, and PRL only in the prostate, were recently generated (V Rouet, RL Bogorad, C Kayser, K Kessal, C Genestie, A Bardier, DR Grattan, B Kelder, JJ Kopchick, PA Kelly \& V Goffin, unpublished observations). This model showed that all the phenotypes linked to prostate tumorigenesis induced by autocrine PRL compared to wild-type littermates (i.e. prostate hypertrophy, histological defects, and PRLR signaling) were reduced or even abolished in double transgenics, assessing the anti-tumor properties of the antagonist in vivo. To our knowledge, this is the first molecule demonstrating the capacity to functionally counteract the pro-tumor actions triggered by local PRL.

Del1-9-G129R-hPRL was also tested in cell systems expressing the constitutively active receptor PRLR-I146L. A single dose of this PRL analog was shown to down-regulate PRLR phosphorylation and STAT5 signaling (significant inhibition lasted up to $24 \mathrm{~h}$ ), which resulted in reduced proliferation over 3 days of both $\mathrm{Ba} / \mathrm{F} 3$ and MCF-7 cells stably expressing PRLR-I146L (Bogorad et al. 2008). This indicates that in this specific case, the 'antagonist' Del1-9-G129RhPRL actually acts as an 'inverse agonist' toward this gainof-function receptor. The molecular (structural) mechanism underlying this effect, as well as the one leading to PRLRI146L constitutive activity, is currently unknown.

Novel views Although the impact of autocrine/paracrine PRL and of gain-of-function PRLR variant(s) in human pathophysiology remains to be more precisely defined, their independence to dopamine regulation supports the need for developing alternative targeting strategies. Data recently accumulated using Del1-9-G129R-hPRL antagonist make the latter a good candidate to counteract the undesirable actions potentially mediated by these 'local' mechanisms of PRLR signaling amplification (Goffin et al. 2006). However, progress is needed to demonstrate first, the ability of Del1-9-G129R-hPRL to inhibit the phenotypes induced by PRLR-I146L in vivo (themselves to be identified), and second, the long-term anti-tumor potency of Del1-9G129R-hPRL toward human tumors, in order to complete ongoing studies involving animal models. Engineering of long-acting version of this pure antagonist is an immediate challenge. As recently discussed (Goffin et al. 2006), PRLR antagonist therapy is not anticipated to have adverse effects, as the absence of PRLR in mice has not shown any sign of strong metabolic disorder, toxicity or lethality. We should remain vigilant, however, since animal models may not fully reflect the outcome of PRL blockade in humans. This is especially true with respect to autocrine PRL, which may exert specific functions that are currently unknown or under-estimated in humans. Since the level of inhibition exerted by competitive antagonists is directly proportional to their concentration relative to the natural ligand, appropriate doses should be evaluated to not achieve complete receptor blockade if required.

\section{Conclusions}

PRL pathophysiology is currently viewed as a minor issue in public health. This is due to the fact that i) dopamine analogs have proven to be very efficient in controlling hyperprolactinemic patients, ii) investigations of the involvement of this hormone in human tumorigenesis failed to provide any clear picture, leading clinicians to forget about it, and iii) clinical, epidemiological and therapeutic studies have exclusively focused on endocrine (systemic) PRL, which more and more appears to represent only a part of this hormonal system. Indeed, as discussed in this article, two novel mechanisms that are acting locally - i.e. independent of pituitary PRL have been recently added into the global PRL scheme (Fig. 1): autocrine/paracrine PRL and gain-of-function PRLR variants. The impact of these novel mechanisms in human pathophysiology must be better understood, as only descriptive reports have been published to date, which suggest their participation in tumorigenesis, but certainly do not prove any causal link. The development of molecules of proven efficacy to target these pathways is of concern to move forward. PRLR antagonists are candidates, but others also exist. The proof-of-concept demonstrating the ability of PRLR antagonists to inhibit the pro-tumor actions triggered by autocrine PRL and/or by PRLR-I146L has been obtained using experimental systems. Now, these data need to be validated using human cell xenograft approaches, as these two 
novel mechanisms seem to be more specific to this species. Although PRL-transfected breast cancer cells have been used in the past to demonstrate the growth-promoting effect of locally over-expressed PRL in xenografts (Liby et al. 2003), there is currently no unified cell model used for targeting autocrine/paracrine PRL actions at preclinical stages of therapeutic molecule development. This is even more true for PRLR-I146L, which is yet to be identified in any cell line classically used in PRL biology.

Tumorigenesis of PRL target tissues may not be the unique pathophysiological context in which inhibitors of PRLR activation may be of interest. Despite the acknowledged efficacy of dopamine agonists for treating prolactinomaassociated hyperprolactinemia, dopamine resistance accounts for $10-15 \%$ of the cases. In such patients, therapeutic strategies include increased doses of the same dopamine analog, use of alternative ones, surgery or radiotherapy (Molitch 2005b). While all above strategies target the pituitary tumor, PRLR antagonist could be viewed as alternative means to treat systemic consequences of hyperprolactinemia by targeting the PRLR in periphery. This would of course imply that they do exert detrimental effect on the volume of pituitary tumors, which is currently unknown. Probably more than dopamine-resistant prolactinomas, medicationinduced hyperprolactinemia has become of major concern for clinical endocrinologists. This condition is classically observed in patients treated for psychiatric disorders using blockers of dopamine D2 receptors. Hence, dopamine agonist therapy is not suitable for treating associated symptomatic hyperprolactinemia. The availability of compounds blocking the PRLR without affecting pituitary D2 receptors may be helpful to improve the condition of such patients. Effective PRLR blockade should indeed restore the physiological functions imbalanced by hyperprolactinemia, including fertility which is often the concern.

\section{Declaration of interest}

The authors declare that there is no conflict of interest that could be perceived as prejudicing the impartiality of the research reported.

\section{Funding}

VG was awarded an Institut National de la Santé et de la Recherche Médicale - Assistance Publique - Hôpitaux de Paris Interface contract, and SB was awarded the 2007 Prix Société Française d'Endocrinologie - Ipsen.

\section{Acknowledgements}

The authors thank all the laboratory members who participated in the studies evoked in this review. We are grateful to Paul Kelly for his helpful discussions and his help in writing this manuscript. Owing to limited space, we could not discuss all aspects of PRL biology, and we apologize to all colleagues who are not cited in this review.

\section{References}

Andersen B \& Rosenfeld MG 2001 POU domain factors in the neuroendocrine system: lessons from developmental biology provide insights into human disease. Endocrine Reviews 22 2-35.

Anderson E, Ferguson JE, Morten H, Shalet SM, Robinson EL \& Howell A 1993 Serum immunoreactive and bioactive lactogenic hormones in advanced breast cancer patients treated with bromocriptine and octreotide. European Journal of Cancer 29A 209-217.

Arendt LM \& Schuler LA 2008 Transgenic models to study actions of prolactin in mammary neoplasia. Journal of Mammary Gland Biology and Neoplasia 13 29-40.

Baudhuin A, Manfroid I, Van De WC, Martial JA \& Muller M 2002 Transcription of the human prolactin gene in mammary cells. Annals of the New York Academy of Sciences 973 454-458.

Ben-Jonathan N, Mershon JL, Allen DL \& Steinmetz RW 1996 Extrapituitary prolactin: distribution, regulation, functions, and clinical aspects. Endocrine Reviews 17 639-669.

Ben Jonathan N, Lapensee CR \& Lapensee EW 2008 What can we learn from rodents about prolactin in humans? Endocrine Reviews 29 1-41.

Bernichtein S, Jeay S, Vaudry R, Kelly PA \& Goffin V 2003a New homologous bioassays for human lactogens show that agonism or antagonism of various analogs is a function of assay sensitivity. Endocrine 20 177-190.

Bernichtein S, Kayser C, Dillner K, Moulin S, Kopchick JJ, Martial JA, Norstedt G, Isaksson O, Kelly PA \& Goffin V $2003 b$ Development of pure prolactin receptor antagonists. Journal of Biological Chemistry 278 35988-35999.

Bogorad RL, Courtillot C, Mestayer C, Bernichtein S, Harutyunyan L, Jomain JB, Bachelot A, Kuttenn F, Kelly PA, Goffin V et al. 2008 Identification of a gain-of-function mutation of the prolactin receptor in women with benign breast tumors. PNAS 105 14533-14538.

Bole-Feysot C, Goffin V, Edery M, Binart N \& Kelly PA 1998 Prolactin and its receptor: actions, signal transduction pathways and phenotypes observed in prolactin receptor knockout mice. Endocrine Reviews 19 225-268.

Bonneterre J, Mauriac L, Weber B, Roche H, Fargeot P, Tubiana-Hulin M, Sevin M, Chollet P \& Cappelaere P 1988 Tamoxifen plus bromocriptine versus tamoxifen plus placebo in advanced breast cancer: results of a double blind multicentre clinical trial. European Journal of Cancer \& Clinical Oncology 24 1851-1853.

Brockman JL, Schroeder MD \& Schuler LA 2002 PRL activates the cyclin D1 promoter via the Jak2/Stat pathway. Molecular Endocrinology 16 774-784.

Broutin I, Jomain JB, Tallet E, Van Agthoven J, Raynal B, Hoos S, Kragelund BB, Kelly PA, Ducruix A, England P et al. 2010 Crystal structure of an affinity-matured prolactin complexed to its dimerized receptor reveals the topology of hormone binding site 2. Journal of Biological Chemistry 285 8422-8433.

Canbay E, Degerli N, Gulluoglu BM, Kaya H, Sen M \& Bardakci F 2004 Could prolactin receptor gene polymorphism play a role in pathogenesis of breast carcinoma? Current Medical Research and Opinion 20 533-540.

Clevenger CV, Chang WP, Ngo W, Pasha TM, Montone KT \& Tomaszewski JE 1995 Expression of prolactin and prolactin receptor in human breast carcinoma. American Journal of Pathology 146 695-705.

Clevenger CV, Furth PA, Hankinson SE \& Schuler LA 2003 The role of prolactin in mammary carcinoma. Endocrine Reviews 24 1-27.

Colao A, Vitale G, Di Sarno A, Spiezia S, Guerra E, Ciccarelli A \& Lombardi G 2004 Prolactin and prostate hypertrophy: a pilot observational, prospective, case-control study in men with prolactinoma. Journal of Clinical Endocrinology and Metabolism 89 2770-2775.

Courtillot C, Plu-Bureau G, Binart N, Balleyguier C, Sigal-Zafrani B, Goffin V, Kuttenn F, Kelly PA \& Touraine P 2005 Benign breast diseases. Journal of Mammary Gland Biology and Neoplasia 10 325-335.

Courtillot C, Chakhtoura Z, Bogorad R, Genestie C, Bernichtein S, Badachi Y, Janaud G, Akakpo JP, Bachelot A, Kuttenn F et al. 2010 Characterization of two constitutively active prolactin receptor variants in a cohort of 95 women with multiple breast fibroadenomas. Journal of Clinical Endocrinology and Metabolism 95 271-279. 
Dagvadorj A, Collins S, Jomain JB, Abdulghani J, Karras J, Zellweger T, Li H, Nurmi M, Alanen K, Mirtti T et al. 2007 Autocrine prolactin promotes prostate cancer cell growth via Janus kinase-2-signal transducer and activator of transcription-5a/b signaling pathway. Endocrinology 148 3089-3101.

Dagvadorj A, Kirken RA, Leiby B, Karras J \& Nevalainen MT 2008 Transcription factor signal transducer and activator of transcription 5 promotes growth of human prostate cancer cells in vivo. Clinical Cancer Research 14 1317-1324.

Davis SW, Castinetti F, Carvalho LR, Ellsworth BS, Potok MA, Lyons RH, Brinkmeier ML, Raetzman LT, Carninci P \& Mortensen AH 2010 Molecular mechanisms of pituitary organogenesis: in search of novel regulatory genes. Molecular and Cellular Endocrinology 323 4-19.

Diogenes A, Patwardhan AM, Jeske NA, Ruparel NB, Goffin V, Akopian AN \& Hargreaves KM 2006 Prolactin modulates TRPV1 in female rat trigeminal sensory neurons. Journal of Neuroscience 26 8126-8136.

Dorshkind K \& Horseman ND 2000 The roles of prolactin, growth hormone, insulin-like growth factor-I, and thyroid hormones in lymphocyte development and function: insights from genetic models of hormone and hormone receptor deficiency. Endocrine Reviews 21 292-312.

Eyal O, Jomain JB, Kessler C, Goffin V \& Handwerger S 2007 Autocrine prolactin inhibits human uterine decidualization: a novel role for prolactin. Biology of Reproduction 76 777-783.

Foitzik K, Langan EA \& Paus R 2009 Prolactin and the skin: a dermatological perspective on an ancient pleiotropic peptide hormone. Journal of Investigative Dermatology 129 1071-1087.

Gellersen B, Kempf R, Telgmann R \& DiMattia GE 1994 Nonpituitary human prolactin gene transcription is independent of Pit-1 and differentially controlled in lymphocytes and in endometrial stroma. Molecular Endocrinology 8 356-373.

Gerlo S, Davis JR, Mager DL \& Kooijman R 2006 Prolactin in man: a tale of two promoters. BioEssays 28 1051-1055.

Gill S, Peston D, Vonderhaar BK \& Shousha S 2001 Expression of prolactin receptors in normal, benign, and malignant breast tissue: an immunohistological study. Journal of Clinical Pathology 54 956-960.

Ginsburg E \& Vonderhaar BK 1995 Prolactin synthesis and secretion by human breast cancer cells. Cancer Research 55 2591-2595.

Glasow A, Horn LC, Taymans SE, Stratakis CA, Kelly PA, Kohler U, Gillespie J, Vonderhaar BK \& Bornstein SR 2001 Mutational analysis of the PRL receptor gene in human breast tumors with differential PRL receptor protein expression. Journal of Clinical Endocrinology and Metabolism 86 3826-3832.

Goffin V, Struman I, Mainfroid V, Kinet S \& Martial JA 1994 Evidence for a second receptor binding site on human prolactin. Journal of Biological Chemistry 269 32598-32606.

Goffin V, Kinet S, Ferrag F, Binart N, Martial JA \& Kelly PA 1996 Antagonistic properties of human prolactin analogs that show paradoxical agonistic activity in the $\mathrm{Nb} 2$ bioassay. Journal of Biological Chemistry 271 16573-16579.

Goffin V, Bernichtein S, Touraine P \& Kelly PA 2005 Development and potential clinical uses of human prolactin receptor antagonists. Endocrine Reviews 26 400-422.

Goffin V, Touraine P, Culler MD \& Kelly PA 2006 Drug insight: prolactinreceptor antagonists, a novel approach to treatment of unresolved systemic and local hyperprolactinemia? Nature Clinical Practice. Endocrinology \& Metabolism 2 571-581.

Goffin V, Tallet E, Jomain JB \& Kelly PA 2007 Development of prolactin receptor antagonists: same goal, different ways. Recent Patents on Endocrine, Metabolic \& Immune Drug Discovery 1 41-52.

Hartmann LC, Sellers TA, Frost MH, Lingle WL, Degnim AC, Ghosh K, Vierkant RA, Maloney SD, Pankratz VS, Hillman DW et al. 2005 Benign breast disease and the risk of breast cancer. New England Journal of Medicine 353 229-237.

Horseman ND, Zhao W, Montecino-Rodriguez E, Tanaka M, Nakashima K, Engle SJ, Smith F, Markoff E \& Dorshkind K 1997 Defective mammopoiesis, but normal hematopoiesis, in mice with a targeted disruption of the prolactin gene. EMBO Journal 16 6926-6935.
Hughes LE, Mansel RE \& Webster DJT 2000 Benign disorders and diseases of the breast - concepts and clinical management. Edn 2, pp 21-34. Eds LE Hughes, RE Mansel \& DJT Webster. WB Saunders: Philadelphia.

Hugo ER, Borcherding DC, Gersin KS, Loftus J \& Ben Jonathan N 2008 Prolactin release by adipose explants, primary adipocytes, and LS14 adipocytes. Journal of Clinical Endocrinology and Metabolism 93 4006-4012.

Hummer M \& Huber J 2004 Hyperprolactinaemia and antipsychotic therapy in schizophrenia. Current Medical Research and Opinion 20 189-197.

Jomain JB, Tallet E, Broutin I, Hoos S, Van Agthoven J, Ducruix A, Kelly PA, Kragelund BB, England P \& Goffin V 2007 Structural and thermodynamical bases for the design of pure prolactin receptor antagonists. X-ray structure of Del1-9-G129R-hPRL. Journal of Biological Chemistry 282 33118-33131.

Key T, Appleby P, Barnes I \& Reeves G 2002 Endogenous sex hormones and breast cancer in postmenopausal women: reanalysis of nine prospective studies. Journal of the National Cancer Institute 94 606-616.

Kindblom J, Dillner K, Sahlin L, Robertson F, Ormandy C, Tornell J \& Wennbo H 2003 Prostate hyperplasia in a transgenic mouse with prostatespecific expression of prolactin. Endocrinology 144 2269-2278.

Knegtering $\mathrm{H}$, van der Moolen AE, Castelein S, Kluiter $\mathrm{H}$ \& van den Bosch RJ 2003 What are the effects of antipsychotics on sexual dysfunctions and endocrine functioning? Psychoneuroendocrinology 28 (Suppl 2) 109-123.

Lachelin GC, Yen SC \& Alksne JF 1977 Hormonal changes following hypophysectomy in humans. Obstetrics and Gynecology 50 333-339.

Lapensee E \& Ben Jonathan N 2010 Novel roles of prolactin and estrogens in breast cancer: resistance to chemotherapy. Endocrine-Related Cancer $\mathbf{1 7}$ R91-R107.

Leav I, Merk FB, Lee KF, Loda M, Mandoki M, McNeal JE \& Ho SM 1999 Prolactin receptor expression in the developing human prostate and in hyperplastic, dysplastic, and neoplastic lesions. American Journal of Pathology 154 863-870.

Lee SA, Haiman CA, Burtt NP, Pooler LC, Cheng I, Kolonel LN, Pike MC, Altshuler D, Hirschhorn JN, Henderson BE et al. 2007 A comprehensive analysis of common genetic variation in prolactin (PRL) and PRL receptor (PRLR) genes in relation to plasma prolactin levels and breast cancer risk: the multiethnic cohort. BMC Medical Genetics 872.

Li H, Ahonen TJ, Alanen K, Xie J, LeBaron MJ, Pretlow TG, Ealley EL, Zhang Y, Nurmi M, Singh B et al. 2004 Activation of signal transducer and activator of transcription 5 in human prostate cancer is associated with high histological grade. Cancer Research 64 4774-4782.

Liby K, Neltner B, Mohamet L, Menchen L \& Ben Jonathan N 2003 Prolactin overexpression by MDA-MB-435 human breast cancer cells accelerates tumor growth. Breast Cancer Research and Treatment 79 241-252.

Liu X, Robinson GW, Wagner KU, Garrett L, Wynshaw-Boris A \& Hennighausen L 1997 Stat5a is mandatory for adult mammary gland development and lactogenesis. Genes and Development 11 179-186.

Manfroid I, Van De WC, Baudhuin A, Martial JA \& Muller M 2005 EGF stimulates Pit-1 independent transcription of the human prolactin pituitary promoter in human breast cancer SK-BR-3 cells through its proximal AP-1 response element. Molecular and Cellular Endocrinology 229 127-139.

Manhes C, Kayser C, Bertheau P, Kelder B, Kopchick JJ, Kelly PA, Touraine P \& Goffin V 2006 Local over-expression of prolactin in differentiating mouse mammary gland induces functional defects and benign lesions, but no carcinoma. Journal of Endocrinology 190 271-285.

McHale K, Tomaszewski JE, Puthiyaveettil R, Livolsi VA \& Clevenger CV 2008 Altered expression of prolactin receptor-associated signaling proteins in human breast carcinoma. Modern Pathology 21 565-571.

Mertani HC, Garcia-Caballero T, Lambert A, Gerard F, Palayer C, Boutin JM, Vonderhaar BK, Waters MJ, Lobie PE \& Morel G 1998 Cellular expression of growth hormone and prolactin receptors in human breast disorders. International Journal of Cancer 79 202-211.

Molitch ME 2003 Dopamine resistance of prolactinomas. Pituitary 6 19-27. Molitch ME 2005a Medication-induced hyperprolactinemia. Mayo Clinic Proceedings 80 1050-1057.

Molitch ME 2005b Pharmacologic resistance in prolactinoma patients. Pituitary 8 43-52.

Molitch ME, Thorner MO \& Wilson C 1997 Management of prolactinomas. Journal of Clinical Endocrinology and Metabolism 82 996-1000. 
Naylor MJ, Lockefeer JA, Horseman ND \& Ormandy CJ 2003 Prolactin regulates mammary epithelial cell proliferation via autocrine/paracrine mechanism. Endocrine 20 111-114.

Nevalainen MT, Valve EM, Ingleton PM, Nurmi M, Martikainen PM \& Harkonen PL 1997 Prolactin and prolactin receptors are expressed and functioning in human prostate. Journal of Clinical Investigation 99 618-627.

Nevalainen MT, Xie J, Torhorst J, Bubendorf L, Haas P, Kononen J, Sauter G \& Rui H 2004 Signal transducer and activator of transcription-5 activation and breast cancer prognosis. Journal of Clinical Oncology 22 2053-2060.

Ormandy CJ, Camus A, Barra J, Damotte D, Lucas BK, Buteau H, Edery M, Brousse N, Babinet C, Binart N et al. 1997 Null mutation of the prolactin receptor gene produces multiple reproductive defects in the mouse. Genes and Development 11 167-178.

Popovic V, Damjanovic S, Micic D, Nesovic M, Djurovic M, Petakov M, Obradovic S, Zoric S, Simic M, Penezic Z et al. 1998 Increased incidence of neoplasia in patients with pituitary adenomas. The Pituitary Study Group. Clinical Endocrinology 49 441-445.

Ramot Y, Biro T, Tiede S, Toth BI, Langan EA, Sugawara K, Foitzik K, Ingber A, Goffin V, Langbein L et al. 2010 Prolactin - a novel neuroendocrine regulator of human keratin expression in situ. FASEB Journal DOI:10.1096/fj.09-146415.

Reynolds C, Montone KT, Powell CM, Tomaszewski JE \& Clevenger CV 1997 Expression of prolactin and its receptor in human breast carcinoma. Endocrinology 138 5555-5560.

Riddle O, Bates RW \& Dykshorn SW 1933 The preparation, identification and assay of prolactin - a hormone of the anterior pituitary. American Journal of Physiology 105 191-216.

Rose-Hellekant TA, Arendt LM, Schroeder MD, Gilchrist K, Sandgren EP \& Schuler LA 2003 Prolactin induces ERalpha-positive and ERalphanegative mammary cancer in transgenic mice. Oncogene 22 4664-4674.

Saito T, Tojo K, Oki Y, Sakamoto N, Matsudaira T, Sasaki T \& Tajima N 2007 A case of prolactin deficiency with familial puerperal alactogenesis accompanying impaired ACTH secretion. Endocrine Journal 54 59-62.

Santen RJ \& Mansel R 2005 Benign breast disorders. New England Journal of Medicine 353 275-285.

Schroeder MD, Symowicz J \& Schuler LA 2002 PRL modulates cell cycle regulators in mammary tumor epithelial cells. Molecular Endocrinology 16 45-57.

Semprini S, Friedrichsen S, Harper CV, McNeilly JR, Adamson AD, Spiller DG, Kotelevtseva N, Brooker G, Brownstein DG, McNeilly AS et al. 2009 Real-time visualization of human prolactin alternate promoter usage in vivo using a double-transgenic rat model. Molecular Endocrinology 23 529-538.

Shaw-Bruha CM, Pirrucello SJ \& Shull JD 1997 Expression of the prolactin gene in normal and neoplastic human breast tissues and human mammary cell lines: promoter usage and alternative mRNA splicing. Breast Cancer Research and Treatment 44 243-253.

Stattin P, Rinaldi S, Stenman UH, Riboli E, Hallmans G, Bergh A \& Kaaks R 2001 Plasma prolactin and prostate cancer risk: a prospective study. International Journal of Cancer 92 463-465.

Stricker P \& Grueter R 1928 Action du lobe antérieur de l'hypophyse sur la montée laiteuse. Comptes Rendus des Séances de la Société de Biologie et de ses Filiales 99 1978-1980.

Tallet E, Rouet V, Jomain JB, Kelly PA, Bernichtein S \& Goffin V 2008 Rational design of competitive prolactin/growth hormone receptor antagonists. Journal of Mammary Gland Biology and Neoplasia 13 105-117.

Touraine P, Martini JF, Zafrani B, Durand JC, Labaille F, Malet C, Nicolas A, Trivin C, Postel-Vinay MC, Kuttenn F et al. 1998 Increased expression of prolactin receptor gene assessed by quantitative polymerase chain reaction in human breast tumors versus normal breast tissues. Journal of Clinical Endocrinology and Metabolism 83 667-674.
Tran TH, Utama FE, Lin J, Yang N, Sjolund AB, Ryder A, Johnson KJ, Neilson LM, Liu C, Brill KL et al. 2010 Prolactin inhibits BCL6 expression in breast cancer through a Stat5a-dependent mechanism. Cancer Research 70 1711-1721.

Tworoger SS \& Hankinson SE 2008 Prolactin and breast cancer etiology: an epidemiologic perspective. Journal of Mammary Gland Biology and Neoplasia 13 41-43.

Tworoger SS, Sluss P \& Hankinson SE 2006 Association between plasma prolactin concentrations and risk of breast cancer among predominately premenopausal women. Cancer Research 66 2476-2482.

Tworoger SS, Eliassen AH, Sluss P \& Hankinson SE 2007 A prospective study of plasma prolactin concentrations and risk of premenopausal and postmenopausal breast cancer. Journal of Clinical Oncology 25 1482-1488.

Vaclavicek A, Hemminki K, Bartram CR, Wagner K, Wappenschmidt B, Meindl A, Schmutzler RK, Klaes R, Untch M, Burwinkel B et al. 2006 Association of prolactin and its receptor gene regions with familial breast cancer. Journal of Clinical Endocrinology and Metabolism 91 1513-1519.

Van Coppenolle F, Slomianny C, Carpentier F, Le Bourhis X, Ahidouch A, Croix D, Legrand G, Dewailly E, Fournier S, Cousse H et al. 2001 Effects of hyperprolactinemia on rat prostate growth: evidence of androgenodependence. American Journal of Physiology. Endocrinology and Metabolism 280 E120-E129.

Wagner KU \& Rui H 2008 Jak2/Stat5 signaling in mammogenesis, breast cancer initiation and progression. Journal of Mammary Gland Biology and Neoplasia 13 93-103.

Walker AM 2007 S179D prolactin: antagonistic agony! Molecular and Cellular Endocrinology 276 1-9.

Welsch CW \& Nagasawa H 1977 Prolactin and murine mammary tumorigenesis: a review. Cancer Research 37 951-963.

Wennbo H, Gebre-Medhin M, Gritli-Linde A, Ohlsson C, Isaksson OG \& Tornell J 1997a Activation of the prolactin receptor but not the growth hormone receptor is important for induction of mammary tumors in transgenic mice. Journal of Clinical Investigation 100 2744-2751.

Wennbo H, Kindblom J, Isaksson OG \& Tornell J $1997 b$ Transgenic mice overexpressing the prolactin gene develop dramatic enlargement of the prostate gland. Endocrinology 138 4410-4415.

Worsham MJ, Raju U, Lu M, Kapke A, Botttrell A, Cheng J, Shah V, Savera A \& Wolman SR 2009 Risk factors for breast cancer from benign breast disease in a diverse population. Breast Cancer Research and Treatment 118 1-7.

Zargar AH, Masoodi SR, Laway BA, Shah NA \& Salahudin M 1997 Familial puerperal alactogenesis: possibility of a genetically transmitted isolated prolactin deficiency. British Journal of Obstetrics and Gynaecology 104 629-631.

Zargar AH, Salahuddin M, Laway BA, Masoodi SR, Ganie MA \& Bhat MH 2000 Puerperal alactogenesis with normal prolactin dynamics: is prolactin resistance the cause? Fertility and Sterility 74 598-600.

Zhang G, Li W, Holle L, Chen N \& Chen WY 2002 A novel design of targeted endocrine and cytokine therapy for breast cancer. Clinical Cancer Research 8 1196-1205.

Zinger M, McFarland M \& Ben Jonathan N 2003 Prolactin expression and secretion by human breast glandular and adipose tissue explants. Journal of Clinical Endocrinology and Metabolism 88 689-696.

\section{Received in final form 31 March 2010 \\ Accepted 6 April 2010 \\ Made available online as an Accepted \\ Preprint 6 April 2010}

